Review began 08/02/2021 Review ended 08/18/2021 Published 08/21/2021

(๑) Copyright 2021 Batista et al. This is an open access article distributed under the terms of the Creative Commons Attribution License CC-BY 4.0., which permits unrestricted use, distribution, and reproduction in any medium, provided the original author and source are credited.

\section{Multiple Primary Malignancies in Head and Neck Cancer: A University Hospital Experience Over a Five-Year Period}

\author{
Marta Vaz Batista ${ }^{1}$, João Ulrich ${ }^{2}$, Luís Costa ${ }^{3}$, Leonor Abreu Ribeiro ${ }^{3}$ \\ 1. Medical Oncology, Hospital Prof. Doutor Fernando Fonseca, Lisboa, PRT 2. Radiotherapy, Centro Hospitalar \\ Universitário de Lisboa Norte, Lisboa, PRT 3. Medical Oncology, Centro Hospitalar Universitário de Lisboa Norte, \\ Lisboa, PRT
}

Corresponding author: Marta Vaz Batista, martafilipavaz@gmail.com

\section{Abstract}

\section{Introduction}

With an estimated incidence of $2 \%-4 \%$ per year, the development of a second primary malignancy (SPM) in patients with head and neck tumors (HNTs) is not a rare event. The present study aimed to (i) assess the frequency of SPMs in patients with HNTs treated in a university hospital over a five-year period and (ii) provide a demographic characterization of these patients.

\section{Methods}

Retrospective single-centre study of patients with more than one primary tumor (including at least one HNT) diagnosed between January 1, 2015, and December 31, 2019. Data were retrieved from patients' clinical records and anonymized for analysis purposes.

\section{Results}

A total of 53 out of 824 (6.43\%) patients with multiple primary malignancies were identified, 18 of which synchronous and 35 metachronous. The median follow-up was 25 months. Thirteen patients were diagnosed with more than one HNT. Forty patients were diagnosed with at least one HNT and one non-HNT. The most frequently diagnosed non-HNT SPMs were lung cancer $(n=17)$ and esophageal cancer $(n=8)$. The five-year survival rate was $53 \%$ for patients with multiple HNSCCs and $47 \%$ for patients with at least one non-HNT (log-rank $\mathrm{p}=0.729$ ). The median overall survival was 14 months for synchronous and 58 months for metachronous SPMs (log-rank $\mathrm{p}=0.002)$.

\section{Conclusion}

Findings from this study highlight the importance of long-term follow-up of HNT patients for early detection of SPMs, increasing the chance of providing treatment with curative intent and improving patient outcomes and survival.

Categories: Otolaryngology, Oncology

Keywords: field cancerization, head and neck cancer, multiple primary malignancies, second primary malignancy head and neck neoplasms

\section{Introduction}

Head and neck tumors (HNTs) represent the seventh most common cancers worldwide, accounting for approximately 890.000 new cases and 450.000 deaths in 2018 [1]. HNTs comprehend a heterogeneity of malignancies arising in the head and neck anatomic region, including in the upper aerodigestive tract (oral cavity, nasal cavity, paranasal sinuses, pharynx, larynx, cervical esophagus), salivary glands, thyroid, associated lymph nodes, soft tissues, and bone [2]. The most common histological type is squamous cell carcinoma (SCC) and its variants [3].

The development of a second primary malignancy (SPM) in patients HNTs is not a rare event. Second tumors can be diagnosed either simultaneously/within six months of the index tumor - synchronous SPM - or more than six months after the index tumour - metachronous SPM. According to Warren and Gates criteria, diagnosis of an SPM requires (a) histologic confirmation of malignancy in both the index and second tumors; (b) that the two malignancies are anatomically separated by normal mucosa; and (c) exclusion of the possibility that the SPM is a metastasis from the index tumour [4].

The occurrence of SPMs has been explained by the concept of field cancerization, first described by Slaughter and colleagues in patients with oropharyngeal SCC [5]. This hypothesis considers that large areas 
of head and neck mucosa are affected by the same carcinogenic exposure, resulting in a wide field of premalignant disease with the same genetic alterations, which can give rise to multiple independent primary tumors [6].

Due to the clinical relevance of SPMs, follow-up of all patients with a primary HNT is recommended, not only to detect relapse and manage treatment-related toxicities but also for early detection of metachronous SPMs $[7,8]$. Indeed, the incidence of SPMs in patients with HNTs is estimated at $2 \%-4 \%$ per year, remaining relatively constant over time [9]. The present study aimed to (i) identify the frequency of SPMs in patients with HNTs treated in a university hospital over a five-year period and (ii) perform a demographic characterization of patients developing SPMs.

\section{Materials And Methods}

This was a single-centre retrospective study conducted in a university hospital in Lisbon. The study was approved by the local Ethics Committee. The clinical records of all patients included in the HNT multidisciplinary tumor board between January 1, 2015, and December 31, 2019, were reviewed.

Inclusion criteria were: (1) male or female patient $\geqslant 18$ years old; (2) diagnosis of at least two malignant lesions confirmed by histopathological examination; (3) at least one of the malignant lesions must be an HNT; (4) patients cases presented in the HNT multidisciplinary tumor board between January 1, 2015, and December 31, 2019.

Exclusion criteria were: (1) patients without histopathological confirmation malignancy; (2) second tumor malignancy suspected to be a metastasis; (3) no demographic and/or clinical information on patient's electronic file.

The following variables were collected from clinical records: year of birth; gender (male/female); smoking habits (active smoker - smokes every day and has smoked at least 100 cigarettes, former smoker - quit smoking at diagnosis but had smoked at least 100 cigarettes, or never smoker - smoked less than 100 cigarettes in the lifetime); alcohol consumption (moderate if $<40 \mathrm{~g} / \mathrm{day}$, heavy if $>40 \mathrm{~g} / \mathrm{day}$, or no alcohol consumption); the number of multiple primary tumors; SPM latency (synchronous/metachronous); therapeutic intervention for each tumor; treatment intent (curative/palliative); and date of death (if applicable). Data were analyzed using IBM SPSS Statistics $23^{\circledR}$. Comparisons were made using chi-square and Fisher's exact test. Kaplan-Meier curves were used to calculate survival.

\section{Results}

A total of 824 patients were assessed in the hospital's HNT multidisciplinary tumour board between January 1, 2015, and December 31, 2019. Of these, 53 patients (6.43\%) had multiple primary malignancies, 18 of which were synchronous tumours and 35 metachronous tumours, and were included in the study. The median follow-up was 25 months. The demographic and clinical characteristics of the study population are shown in Table 1.

Clinical characteristics

Sex

Male

Female

Smoking habits*

Active smoker

Former smoker

19

Never smoker

Missing

13

Alcohol consumption**

Moderate

8

Heavy

No alcohol consumption

2 


\section{Cureus}

Number of tumors/patient

2

3

4

Latency

Synchronous

Metachronous

$35 \quad 66.0$

Location of the primary malignancy

Oral cavity

Pharynx

Larynx

$20 \quad 37.7$

Cervical cancer of unknown primary

Salivary gland

Thyroid

Location of the second primary malignancy - head and neck

Oral cavity

Pharynx

Larynx

Cervical cancer of unknown primary

Thyroid

Location of the second primary malignancy - non-head and neck

Lung

Esophagus

Colon

\section{Hepatocellular carcinoma}

Breast

Stomach

Anal

Skin

Central nervous system

Bladder

Sarcoma

Treatment intent (primary malignancy)

\section{Curative}

Treatment intent (second malignancy)

Curative

Group 


\section{Cureus}

\section{TABLE 1: Clinical characteristics of the study population.}

${ }^{*}$ All active smokers and former smokers with $>20$ pack-year.

**Light or moderate alcohol consumption $<40$ g/day, heavy alcohol consumption $>40 \mathrm{~g} /$ day.

nr: number; CUP: cancer of unknown primary; HNT: head and neck tumor.

The median age at diagnosis of first malignancy was 61 (range 47-83) years. Most patients were male $(\mathrm{n}=50$, 94.3\%). Forty-six patients were diagnosed with two different malignancies, six with three, and one with four. For metachronous tumours, the median time for the development of SPMs was four years. Thirteen patients were diagnosed with more than one HNT. Forty patients were diagnosed with at least one HNT and one nonHNT. The most frequently diagnosed non-HNT SPMs were lung cancer $(n=17)$ and esophageal cancer $(n=8)$. Malignancies most frequently diagnosed in the same patient were larynx and lung cancer $(n=8)$, oropharynx and esophagus cancer $(\mathrm{n}=4)$, and oral cavity and lung cancer $(\mathrm{n}=4)$. Table 2 summarizes the types of cancer found in the same patient. For 46 patients, the first diagnosed HNT was treated with curative intent. Seven patients were treated with palliative intent. SPMs were treated with curative intent in 37 patients. 


\section{Cureus}

\begin{tabular}{|c|c|c|c|c|}
\hline Tumor location 1 & Tumor location 2 & Tumor location 3 & Tumor location 4 & Nr. \\
\hline Oral cavity & Oral cavity & Oral cavity & & 1 \\
\hline Oral cavity & Oral cavity & & & 1 \\
\hline Oral cavity & Oral cavity & & & 1 \\
\hline Oral cavity & Cervical CUP & Prostate & & 1 \\
\hline Oral cavity & Esophagus & & & 1 \\
\hline Oral cavity & Larynx & & & 2 \\
\hline Oral cavity & Breast & & & 1 \\
\hline Oral cavity & Oropharynx & & & 1 \\
\hline Oral cavity & Lung & & & 4 \\
\hline Cervical CUP & Larynx & & & 1 \\
\hline Cervical CUP & Lung & & & 1 \\
\hline Salivary gland & Breast & Central nervous system & & 1 \\
\hline Hypopharynx & Hepatocellular carcinoma & & & 1 \\
\hline Hypopharynx & Oesophagus & & & 1 \\
\hline Hypopharynx & Lung & & & 1 \\
\hline Hypopharynx & Bladder & & & 1 \\
\hline Larynx & Anal & & & 1 \\
\hline Larynx & Oral Cavity & & & 2 \\
\hline Larynx & Colon & & & 2 \\
\hline Larynx & Esophagus & & & 2 \\
\hline Larynx & Skin & & & 1 \\
\hline Larynx & Lung & & & 7 \\
\hline Larynx & Lung & Oral cavity & & 1 \\
\hline Larynx & Central nervous system & Prostate & Renal & 1 \\
\hline Larynx & Thyroid & Esophagus & & 1 \\
\hline Larynx & Oropharynx & & & 1 \\
\hline Larynx & Sarcoma & & & 1 \\
\hline Oropharynx & Oral cavity & & & 1 \\
\hline Oropharynx & Hepatocellular carcinoma & & & 2 \\
\hline Oropharynx & Colon & & & 1 \\
\hline Oropharynx & Esophagus & & & 4 \\
\hline Oropharynx & Stomach & & & 1 \\
\hline Oropharynx & Lung & & & 3 \\
\hline Thyroid & Colon & & & 1 \\
\hline
\end{tabular}

\section{TABLE 2: Types of cancer found within the same patient.}

nr.: number; CUP: cancer of unknown primary. 


\section{Cureus}

The overall survival (OS) of patients diagnosed with SPMs consisting only of HNTs (group 1) and patients diagnosed with SPMs in which at least one was not an HNT (group 2) was compared. Groups were comparable for age at first malignancy diagnosis and age at SPM diagnosis $(\mathrm{p}=0.470$ and $\mathrm{p}=0.384$, respectively). Figure 1 shows the Kaplan-Meier curves for OS in both groups. Five-year survival rate was 53\% for patients with multiple HNTs and $47 \%$ for patients with at least one non-HNT (log-rank $\mathrm{p}=0.729$ ). For most patients (21 out of 36), death was due to cancer progression. Five patients died of infectious causes (three with pneumonia and two with sepsis). For 10 patients, it was not possible to ascertain the cause of death.

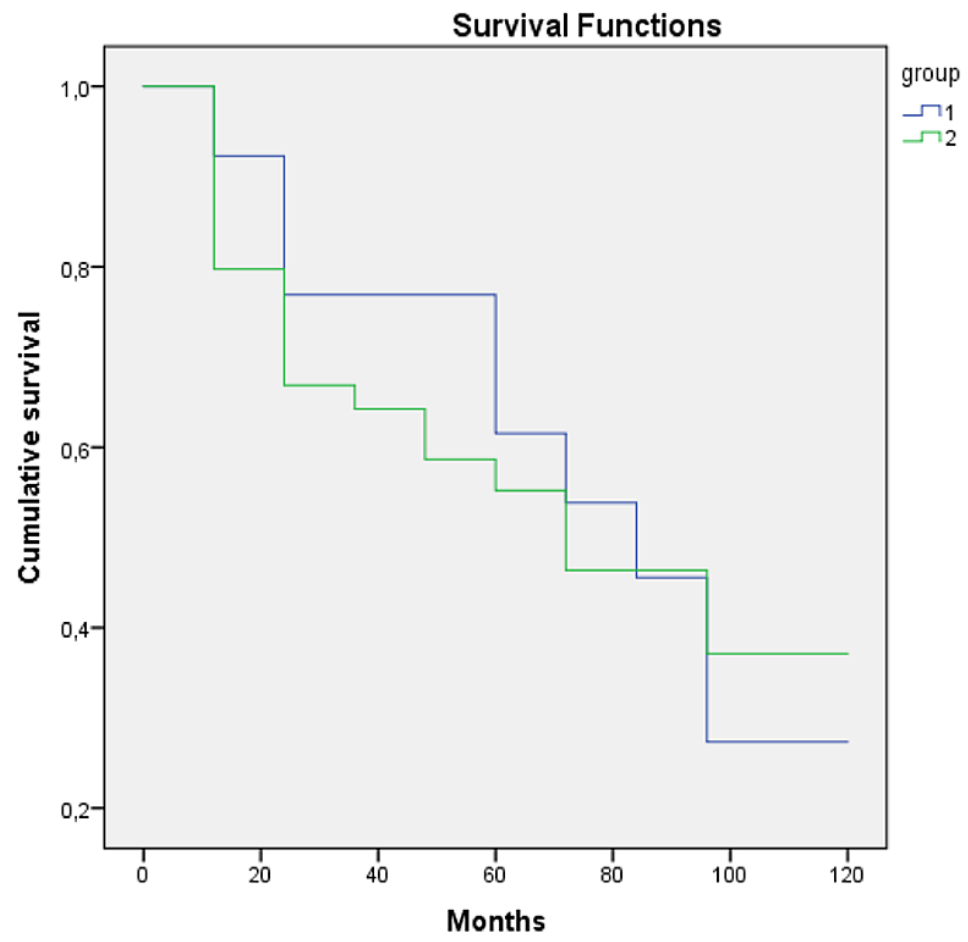

FIGURE 1: Overall survival in patients with only head and neck tumors and with at least one not head and neck tumor.

Kaplan-Meier curves for overall survival for patients with second primary malignancies of the head and neck only (group 1) and with second primary malignancies in which at least one was not a head and neck tumor (group 2).

Median OS was 12.5 months for synchronous and 55 months for metachronous SPMs (log-rank p=0.033). Figure 2 depicts the Kaplan-Meier curves for OS in the two groups. 


\section{Cureus}

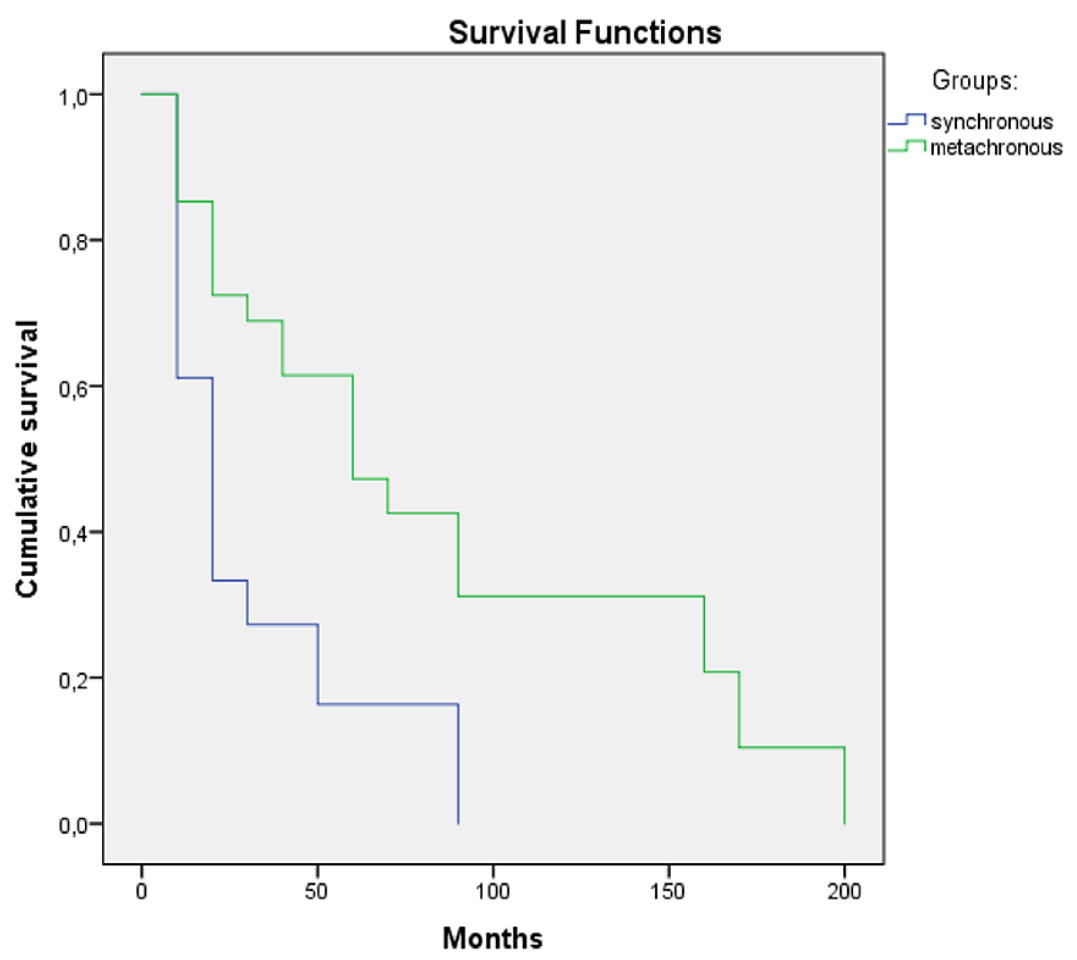

\section{FIGURE 2: Overall survival for patients diagnosed with synchronous and metachronous tumors.}

Kaplan-Meier curves for overall survival for synchronous and metachronous tumors.

\section{Discussion}

Within the five-year period in analysis, $6.43 \%$ of patients in a universe of 824 were identified with an SPM, which is consistent with previous reports [10,11]. From these patients, most (35 out of 53) were diagnosed more than six months after the primary malignancy, with a median time of SPM development of four years.

Lung cancer was the more frequent SPM, accounting for 32.1\%, followed by head and neck (22.6\%) and esophageal (15.1\%) cancers. This data is consistent with previous reports, either from individual data [12] or pooled analyses [13]. Interestingly, the increased risk of lung cancer in patients with HNTs does not seem to be decreasing over the years, as opposed to head and neck and esophagus cancers [14].

As expected, most SPMs developed had acknowledged common risk factors with HNT [15]. Unfortunately, due to this study's retrospective nature, relevant demographic data was missing, as alcohol consumption habits in most patients (67.9\%) and smoking habits in $24.5 \%$. Still, most patients for whom data was available had smoking and alcohol consumption habits.

Most malignancies were treated with curative intent ( $86.8 \%$ of first diagnosed cancers and $69.8 \%$ of SPMs), which is in line with previous reports [10]. Although not statistically significant, a trend was found towards inferior OS when SPMs were not HNTs, which was also reported by other authors [11]. Also consistently with previous studies, patients with metachronous SPMs had a better prognosis than those with synchronous SPMs [16]. Missing data and the small number of patients enrolled precluded the identification of a potential correlation between other clinical variables and increased risk of SPMs.

Since this was a retrospective study, we were only able to analyse demographic data that were previous collected. Like previously said, smoking or drinking habits were missing in more than half of patients. We cannot also exclude a sample bias. As so, our results have to be seen as hypothesis generator.

Even so, our findings highlight the importance of long-term follow-up of these patients for early detection of SPMs, as recommended by European and American clinical practice guidelines $[7,8]$.

\section{Conclusions}

Follow-up visits should focus on early recognition of signs, symptoms, and/or imaging findings suggestive 
of SPMs. Early SPM detection increases the chance of providing treatment with curative intent and has the potential to improve patient outcomes. In our institution, most SPMs were treated with curative intent, and we believe that this might be explained by the regular follow-up politics adopted, that follows international guidelines. It is well acknowledged that preventive medicine has an important impact in the clinical outcomes of these patients, a fact that the study authors reinforce.

\section{Additional Information \\ Disclosures}

Human subjects: Consent was obtained or waived by all participants in this study. Comissão de Ética do Centro Académico de Medicina de Lisboa issued approval 60/21. "O projeto citado em epígrafe, obteve, na reunião ocorrida em 9 de Abril de 2021, parecer favorável da Comissão de Ética (.)". Animal subjects: All authors have confirmed that this study did not involve animal subjects or tissue. Conflicts of interest: In compliance with the ICMJE uniform disclosure form, all authors declare the following: Payment/services info: All authors have declared that no financial support was received from any organization for the submitted work. Financial relationships: All authors have declared that they have no financial relationships at present or within the previous three years with any organizations that might have an interest in the submitted work. Other relationships: All authors have declared that there are no other relationships or activities that could appear to have influenced the submitted work.

\section{References}

1. Bray F, Ferlay J, Soerjomataram I, Siegel RL, Torre LA, Jemal A: Erratum: Global cancer statistics 2018: GLOBOCAN estimates of incidence and mortality worldwide for 36 cancers in 185 countries. CA Cancer J Clin. 2020, 68:394-424. 10.3322/caac.21609

2. Chow LQ: Head and neck cancer. N Engl J Med. 2020, 382:60-72. 10.1056/NEJMra1715715

3. Pathak J, Swain N, Patel S, Poonja L: Histopathological variants of oral squamous cell carcinomainstitutional case reports. J Oral Maxillofac Pathol. 2014, 18:143-5. 10.4103/0973-029X.131945

4. Warren S, Gates O: Multiple primary malignant tumors. A survey of the literature and a statistical study . Am J Cancer. 1932, 16:1358-414.

5. Slaughter SP, Southwick HW, Smejkal W: Field cancerization in oral stratified squamous epithelium; clinical implications of multicentric origin. Cancer. 1953, 6:963-8. 10.1002/1097-0142(195309)6:5963::aidcncr28200605153.0.co;2-q

6. Tabor MP, Brakenhoff RH, Ruijter-Schippers HJ, Van Der Wal JE, Snow GB, Leemans CR, Braakhuis BJ: Multiple head and neck tumors frequently originate from a single preneoplastic lesion . Am J Pathol. 2002, 161:1051-60. 10.1016/S0002-9440(10)64266-6

7. Machiels JP, René Leemans C, Golusinski W, Grau C, Licitra L, Gregoire V: Squamous cell carcinoma of the oral cavity, larynx, oropharynx and hypopharynx: EHNS-ESMO-ESTRO Clinical Practice Guidelines for diagnosis, treatment and follow-up. Ann Oncol. 2020, 31:1462-75. 10.1016/j.annonc.2020.07.011

8. National Comprehensive Cancer Network. Head and Neck Cancers (version 2.2021). (2021). Accessed: 2 May 2021: https://www.nccn.org/login?ReturnURL=https://www.nccn.org/professionals/physician_gls/pdf/headand-neck.pdf.

9. León X, García J, López M, Rodrigues C, Gutierrez A, Quer M: Risk of onset of second neoplasms and successive neoplasms in patients with a head and neck index tumour. Acta Otorrinolaringol Esp. 2020, 71:915. 10.1016/j.otoeng.2018.11.002

10. Ng SP, Pollard C 3rd, Kamal M, et al.: Risk of second primary malignancies in head and neck cancer patients treated with definitive radiotherapy. NPJ Precis Oncol. 2019, 3:22. 10.1038/s41698-019-0097-y

11. Kim SY, Roh JL, Yeo NK, Kim JS, Lee JH, Choi SH, Nam SY: Combined 18F-fluorodeoxyglucose-positron emission tomography and computed tomography as a primary screening method for detecting second primary cancers and distant metastases in patients with head and neck cancer. Ann Oncol. 2007, 18:1698703. 10.1093/annonc/mdm270

12. León X, Del Prado Venegas M, Orús C, Kolañczak K, García J, Quer M: Metachronous second primary tumours in the aerodigestive tract in patients with early stage head and neck squamous cell carcinomas. Eur Arch Otorhinolaryngol. 2005, 262:905-9. 10.1007/s00405-005-0922-5

13. Chuang SC, Scelo G, Tonita JM, et al.: Risk of second primary cancer among patients with head and neck cancers: a pooled analysis of 13 cancer registries. Int J Cancer. 2008, 123:2390-6. 10.1002/ijc.23798

14. Jégu J, Binder-Foucard F, Borel C, Velten M: Trends over three decades of the risk of second primary cancer among patients with head and neck cancer. Oral Oncol. 2013, 49:9-14. 10.1016/j.oraloncology.2012.06.018

15. Rothman KJ: Epidemiology of head and neck cancer . Laryngoscope. 1978, 88:435-8. 10.1288/00005537197803000-00007

16. Priante AV, Castilho EC, Kowalski LP: Second primary tumors in patients with head and neck cancer . Curr Oncol Rep. 2011, 13:132-7. 10.1007/s11912-010-0147-7 